\title{
Parents' views on their children's use of eye drops and willingness to accept a new sustained-release subconjunctival injection
}

This article was published in the following Dove Press journal:

Clinical Ophthalmology

25 October 2017

Number of times this article has been viewed

\section{Semra Ozdemir ${ }^{1, *}$ \\ Hong King Wu',* \\ Eric A Finkelstein \\ Tina T Wong ${ }^{2}$}

'Signature Program in Health Services and Systems Research, Duke-NUS

Medical School Singapore, ${ }^{2}$ Glaucoma

Department, Singapore National Eye

Centre, Singapore

*These authors contributed equally to this work
Correspondence: Tina T Wong Glaucoma Department, Singapore National Eye Centre, II Third Hospital Avenue, Singapore 16875I, Singapore

Tel +6563228313

Fax +65 62263395

Email tina.wong.t.l@singhealth.com.sg
Aim: The objectives of this study were to explore parents' views about their children's use of regular eye drops and whether they would consider a sustained-release subconjunctival injection as a replacement for daily drops.

Methods: A survey was conducted with 134 parents of children with chronic eye diseases at the Singapore National Eye Centre. Parents were asked their views about their children's use of eye drops and were then presented with a discrete choice experiment that, via a series of trade-off tasks, allowed for estimating demand for a series of hypothetical subconjunctival injections that varied along product features, including interval between administrations, risk of complications, out-of-pocket cost and whether it is recommended by the patient's treating physician.

Results: Results showed that the vast majority of parents did not find administration of eye drops to be inconvenient (78\%) nor did children complain about using daily eye drops $(78 \%)$. Furthermore, only about half of parents whose child missed doses stated concerns about the consequences of non-compliance. The discrete choice experiment revealed that only one in five parents would consider a subconjunctival injection for their children. These parents tended to be more concerned about the consequences of non-compliance with eye drops, had children who administered the drops themselves or had other chronic disease requiring regular medication. Among these parents, risk of complications had the largest effect on injection uptake.

Conclusion: This study shows that parents do not find administration of daily eye drops to be a significant burden. As a result, most would not consider a subconjunctival injection unless risk of complications was extremely small.

Keywords: sustained-release subconjunctival injection, parent preferences, children's use of eye drops

\section{Introduction}

Topical administration of eye drops is the primary method of delivering eye medicine for chronic eye conditions. Such medicated eye drops can be effective in reducing the rate of disease progression if they are administered according to the prescribed regimen. Poor compliance with daily eye drops may lead to poor disease control and progressive visual loss, leading to blindness. ${ }^{1-3}$ This is especially concerning in pediatric patients who may not fully comprehend the seriousness of non-compliance and whose parents may not be able to fully monitor administration.

Alternative routes of drug delivery are in development. ${ }^{4}$ One strategy already being tested in clinical trials is a subconjunctival injection of liposomal latanoprost that releases the appropriate daily drug dosage over an extended period of up to several months. ${ }^{5}$ This mechanism of drug delivery avoids the challenges that come with 
daily medication use and has the potential to increase both adherence and eye health. Yet, it presents alternative concerns. It requires a minimally invasive procedure performed every few months in the eye clinic. This is something that many children may not want to repeatedly undergo. As with any procedure, there is also a small chance of complications, such as conjunctivitis, subconjunctival scarring and injury to the deeper layers of the eye, as well as the risks of infection and subconjunctival scarring from multiple injections in the long term. These risks, combined with the likely increased cost compared with daily medication use, could further reduce parental enthusiasm for the technology.

The objective of this study was to field a survey, including a discrete choice experiment (DCE), to increase our understanding of factors that influence parents' demand for such a technology. We first explore parent's experiences and attitudes about their children's use of regular eye drops for chronic eye diseases. Utilizing DCE tasks, we then ask whether they would ever consider opting for an injectable solution for their children and explore the relative influence of select product-specific and family-specific factors on this decision. Product-specific factors include interval between injections, risk of complications, annual out-of-pocket cost, and whether it is recommended by the patient's treating physician. We hypothesize that all of these factors will influence potential demand but that even a very small risk of complications will greatly reduce stated uptake (ie, demand). This is because many parents will not want to put their children at increased risk for an elective procedure. ${ }^{6}$ Yet, many studies have shown that physician's recommendations strongly influence patient's treatment decisions. ${ }^{7}$ It is possible that a physician recommendation could offset concerns over risks and cost.

Family characteristics include who in the household administers the eye drops, whether the child complains about the daily use of eye drops, how concerned parents are about non-compliance and whether the child has other chronic diseases requiring regular medication. We expect that parents whose child administers eye drops themselves, whose child complains about eye drops, who have concerns about their child's compliance with his/her eye drops and/or whose child has other chronic diseases requiring regular medication will be more willing to adopt the new technology.

By allowing for independent assessment of the relative contribution of select features of the new technology, a DCE represents a novel approach to increase our understanding of parents' preferences over different modes of administration of daily eye mediation. ${ }^{8,9}$ Findings will help increase our understanding of the current challenges that parents face in ensuring that their children are adherent to eye medications and the extent to which this new technology could be a potential solution.

\section{Methods Study participants}

A survey was conducted with parents of pediatric patients (aged 1-18 years) at the outpatient clinics at the Singapore National Eye Centre (SNEC), the largest eye center in Singapore. Patients who have chronic eye disease were identified from the medical records and their parents were approached by a trained interviewer for consent to participate in a brief survey. Only parents whose children have been treated with medicated eye drops regularly were eligible for the study. After informed consent was obtained, the questionnaire was administered via face-to-face interviews in English, the primary language in Singapore. Data collection occurred between May and June 2016. Of the 160 eligible parents who were approached, 134 agreed to participate. The study was ethically reviewed and approved by the Institutional Review Board of Singapore Health Services.

\section{Survey development}

The questionnaire contained questions on who administers the eye drops, whether the child complains about the daily use of eye drops, whether the parent is concerned about non-compliance with eye drops, and sociodemographic characteristics.

Prior to the DCE portion, respondents were told that the injectable solution would replace all eye drops that the child is using and that the solution would be at least as effective as eye drops, with greater effectiveness resulting for children who are not fully adherent. The injection would be administered by an ophthalmologist with the child undergoing either moderate sedation or general anesthesia, depending on age and the child's ability to cooperate during the procedure. Parents were told that general anesthesia is recommended as first line for younger children or those unlikely to cooperate during the procedure but that moderate sedation is recommended for children aged $>8$ years. (Supplementary material 1 provides the full survey instrument).

Parents were told that candidate injections varied across 4 primary features, termed attributes: 1 ) the interval between injections, 2) the annual out-of-pocket cost of the injections, 3 ) the risk of complications, and 4) whether or not it was recommended by child's treating physician over daily eye drops. The interval between injections ranged from 3 to 12 months. The levels of out-of-pocket costs spanned from $\$ 0$ to $\$ 2,000$ a year. Although the cost of injection is expected to be higher than the costs of eye drops, free injections might 
be possible if the insurance companies fully cover the cost. The risk of complications included conjunctivitis and injury to the deeper layers of the eye and ranged from $0 \%$ to $0.1 \%$. Physician recommendation was set up such that only one of the options is recommended by the physician or no recommendation is provided. Table 1 provides the full list of attributes and their levels used in the study. These attributes and their levels were selected based on a series of cognitive interviews with a convenience sample of 9 respondents and discussions with ophthalmologists.

After the introduction of the attributes, in a series of DCE tasks, respondents were offered 3 options of treatment for their child - continuing with eye drops or opting for 2 variants of subconjunctival injections that differed by levels of the attributes described previously. Respondents were asked to identify their most preferred option and second most preferred option among the 3 alternatives. An example is shown in Figure 1. This question format, which provides information on the full ranking of the alternatives within a choice set, was used to maximize the amount of data available for model estimation.

The DCE tasks were constructed via an experimental design that required identifying the specific attribute level for each alternative and matching of the alternatives in each DCE task. The experimental design was created using SAS (SAS Institute, Cary, NC, USA $)^{10}$ and produced 16 tasks that were then divided into 2 blocks of 8 tasks to reduce cognitive burden on respondents. Each respondent was randomly assigned to one of the blocks and answered 10 DCE tasks in total. Respondents were also asked to answer 2 additional tasks. One task was designed to test whether respondents paid attention to the levels shown. ${ }^{11}$ In this task, respondents were presented with 2 injections where one of the injection alternatives was better than the other injection. Respondents

Table I Product attributes and levels used

\begin{tabular}{ll}
\hline Attribute & Level \\
\hline Interval between & Every 3 months \\
injections & Every 6 months \\
& Every I2 months \\
Risk of complication & $0 \%(=0$ patients) \\
per injection & $0.01 \%(=1$ in 10,000 patients) \\
& $0.10 \%(=10$ in 10,000 patients) \\
Out-of-pocket cost & $\$ 0$ \\
per year & $\$ 300$ \\
& $\$ 1,000$ \\
Doctor's & $\$ 2,000$ \\
recommendation & Recommends injection A \\
& Recommends injection B \\
& Recommends eye drops \\
\hline
\end{tabular}

Note: Currency used is Singapore dollars. who did not choose the injection with better attributes were excluded from the study. The second task was a hold-out task created to evaluate the performance of the model by investigating whether the uptake predicted from the model (excluding the hold-out task) is similar to the percentage of respondents who choose injections $\mathrm{A}$ and $\mathrm{B}$ in the hold-out task. ${ }^{12}$ An accurate prediction of the percentage choice of injections $\mathrm{A}$ and $\mathrm{B}$ by the model estimates provides additional credibility to the study results.

\section{Analysis of the DCE data}

As a first step, respondents were divided into 2 groups based on their responses to the DCE tasks: potential adopters and non-adopters. Potential adopters refer to respondents who chose an injection as their first choice in at least one of the choice tasks. Non-adopters refer to respondents who always chose eye drops as their first choice in all choice tasks. A binary logistic regression was used to explore the family characteristics that predict being a potential adopter. The dependent variable was assigned 1 if the respondent was identified as a potential adopter and 0 otherwise. The independent variables were whether child administers eye drops themselves, whether child complains about using eye drops, whether parent is concerned about their child's (non)compliance with his/her existing eye drops, and whether child has other chronic disease requiring regular medication. An independent variable was considered statistically significant if the $p$-value was $<0.10$.

Data from DCEs are routinely analyzed using random utility models. Random utility models assume that the utility an individual receives from a product can be modeled based on the attribute levels of that product, and that for each choice task the individual will choose either the injectable solution or eye drops, depending on which one would provide the higher level of utility. Utility of injections was modeled as:

$$
\begin{aligned}
\mathrm{V}= & \beta_{\mathrm{i}} \text { Interval }- \text { between }- \text { injections }+\beta_{\text {Cost }} \text { Cost } \\
& +\beta_{\text {Comp } 0.01 \%} \text { Complication } 0.01 \% \\
& +\beta_{\text {Comp } 0 \%} \text { Complication } 0 \% \\
& +\beta_{\mathrm{DrRec}} \text { DrRecommendation } \\
& +\beta_{\mathrm{ASC}} \mathrm{ASC}_{\text {Eyedrops }}+\varepsilon
\end{aligned}
$$

where $\mathrm{V}$ denotes the utility, the $\beta$ coefficients denote the marginal utility of each product attribute, $\varepsilon$ denotes the unobserved utility, and $\mathrm{ASC}_{\text {Eyedrops }}$ denotes the alternative specific constant for eye drops, capturing the average effect of attributes not used in the study on the utility of eye drops relative to injections. 
Suppose that these options are available for your child

\begin{tabular}{|c|c|c|c|}
\hline & Injection A & Injection B & Eye drops \\
\hline $\begin{array}{l}\text { Frequency of } \\
\text { injection }\end{array}$ & Every 6 months & Every 3 months & \multirow{3}{*}{$\begin{array}{l}\text { My child continues } \\
\text { using eye drops as } \\
\text { he/she does now }\end{array}$} \\
\hline $\begin{array}{l}\text { Risk of complication } \\
\text { per injection }\end{array}$ & $\begin{array}{c}1 \text { in } \\
10,000 \text { patients }\end{array}$ & 0 patients & \\
\hline \multirow{2}{*}{$\begin{array}{l}\text { Out-of-pocket } \\
\text { cost per year }\end{array}$} & $\$ 1,000$ & $\$ 300$ & \\
\hline & Injection A & Injection B & Eye drops \\
\hline \multicolumn{4}{|l|}{$\begin{array}{l}\text { Label your most } \\
\text { preferred option "1" }\end{array}$} \\
\hline $\begin{array}{l}\text { Then label your } \\
\text { second most } \\
\text { preferred option "2" }\end{array}$ & & & \\
\hline
\end{tabular}

Figure I Example choice task.

Since respondents were asked to rank the options, a rank-ordered logit model was used to analyze the DCE data. Linearity of numerical attributes was tested and the attributes that were found to be nonlinear were estimated using dummy variables. Given that the risk of complications was described per injection, we expected interaction effects between interval between injections and risk of complications. The preliminary models showed that the interaction effects were not statistically significant; thus, they were not included in the final model.

The analysis was limited to potential adopters as nonadopters were considered "out of the market" such that their preferences over different attribute levels are of little interest.

The model estimates were used to calculate the relative importance of each attribute conditional on the levels used in the analysis and to calculate uptake of candidate products. Supplementary material 2 provides detailed information on the calculation of relative attribute importance and uptake. We used STATA version 12 for all statistical analysis.

\section{Results}

The characteristics of the respondents (parents) and their children are presented in Table 2. About two-thirds of the respondents were female, which reflected the tendency of mothers to perform caregiving duties for their children. The majority of the sample was Chinese (90\%) and university degree holders $(71 \%)$, and the average age was 43.7 years. About half of the children were male, and the average age was 10.6 years. An overwhelming majority of the patients were on follow-up for myopia (96\%), for which they used 1 type of eye drops once a day. This is reflective of the pediatric ophthalmology service offered at SNEC, which has a strong reputation of research in delaying myopia progression with atropine eye drops.

Most parents (78\%) reported that their children did not complain about using eye drops. About one-third of the respondents reported that their child administers the eye drops themselves. Among parents who administer eye drops, most (78\%) did not find administering eye drops for their children to be inconvenient. Among parents who reported that their child misses eye drops, only about half the parents $(53 \%)$ were concerned about the consequences of non-compliance. The majority of children ( $85 \%$ ) uses eye drops once a day and about $12 \%$ has other chronic diseases that require regular medication.

Only 4 out of 134 respondents failed the choice task testing respondent attention; they were excluded from the DCE analysis. Out of the remaining 130 respondents, only 31 were potential adopters of injections (23.8\%) and 99 were 
Table 2 Family characteristics $(\mathrm{N}=134)$

\begin{tabular}{|c|c|}
\hline \multicolumn{2}{|l|}{ Family characteristics } \\
\hline Parent age & 43.7 years \\
\hline Patient age & 10.6 years \\
\hline Parent female gender & $62.0 \%$ \\
\hline Patient female gender & $47.8 \%$ \\
\hline \multicolumn{2}{|l|}{ Eye disease, $\%$} \\
\hline Myopia & 95.5 \\
\hline Glaucoma & 1.5 \\
\hline Others & 3.0 \\
\hline Duration since diagnosis & 57.1 months \\
\hline Duration of eye drop usage & 23.6 months \\
\hline \multicolumn{2}{|l|}{ Types of eye drops used, $\%$} \\
\hline I type & 96.3 \\
\hline 2 types & 1.5 \\
\hline 3 types & 0 \\
\hline 4 or more types & 2.2 \\
\hline \multicolumn{2}{|l|}{ Frequency of eye drop usage, $\%$} \\
\hline Once a day & 85.1 \\
\hline Twice a day & 3.7 \\
\hline Three times a day & 0.7 \\
\hline Four or more & 0.7 \\
\hline Others & 9.7 \\
\hline \multicolumn{2}{|c|}{ Child has other chronic disease requiring regular medication, \% } \\
\hline Yes & 11.8 \\
\hline No & 88.2 \\
\hline \multicolumn{2}{|l|}{ Child complains about usage of eye drops, $\%$} \\
\hline Often & 2.2 \\
\hline Sometimes & 11.2 \\
\hline Rarely & 8.2 \\
\hline Never & 78.4 \\
\hline Child administers eye drops him/herself & 33.6 \\
\hline \multicolumn{2}{|c|}{ (If parents administer eye drops) Parents find administering eye drops } \\
\hline \multicolumn{2}{|c|}{ inconvenient $(\mathrm{N}=89)$, \% } \\
\hline Yes, very & 5.6 \\
\hline Yes, somewhat & 16.9 \\
\hline No & 77.5 \\
\hline Child has ever missed eye drops before & 65.7 \\
\hline \multicolumn{2}{|c|}{ (If child has ever missed eye drops) Parents concerned about } \\
\hline \multicolumn{2}{|c|}{ consequences of non-compliance $(\mathrm{N}=88), \%$} \\
\hline Very concerned & 19.3 \\
\hline Somewhat concerned & 33.0 \\
\hline Somewhat unconcerned & 15.9 \\
\hline Very unconcerned & 31.8 \\
\hline
\end{tabular}

non-adopters $(76.2 \%)$. Parents were more likely to be potential adopters if they reported that eye drops were administered by the child (odds ratio [OR]: 2.36, $p$-value: 0.071 ), if they were concerned about the consequences of non-compliance to eye drops (OR: 2.50, $p$-value: 0.040 ) and if the child has other chronic disease requiring regular medication (OR: 3.59, $p$-value: 0.037) (Table 3). Child complaining about the daily use of eye drops was found to be not significant at the $10 \%$ level.

Rank-ordered logit model estimates (Supplementary material 3) show that, as hypothesized, potential adopters
Table 3 Logistic model identifying predictors of being a potential adopter

\begin{tabular}{llll}
\hline & $\begin{array}{l}\text { Odds } \\
\text { ratio }\end{array}$ & $\begin{array}{l}\text { Standard } \\
\text { error }\end{array}$ & p-value \\
\hline $\begin{array}{l}\text { Parents were concerned about the } \\
\text { consequences of non-compliance to }\end{array}$ & 2.50 & I.II & 0.040 \\
eye drops & & & \\
$\begin{array}{l}\text { Eye drops were administered by the child } \\
\text { Child complains about eye drops }\end{array}$ & 2.36 & 1.12 & 0.071 \\
$\begin{array}{l}\text { Child has other chronic disease requiring } \\
\text { regular medication }\end{array}$ & 3.59 & 0.89 & 0.566 \\
$\begin{array}{l}\text { Constant } \\
\text { Log likelihood }\end{array}$ & 0.12 & 0.05 & 0.037 \\
\hline
\end{tabular}

preferred injections with a longer interval between administrations, lower risk of complications and lower cost. A doctor's recommendation also increased the demand. Risk of complications was the most important attribute (44.3\%), followed by cost $(27.8 \%)$, interval between injections (16.4\%) and whether the physician recommended the injection (11.6\%). The predictive power of the model was confirmed by its precision in predicting the uptake of the hold-out task. The model predicted an injection uptake of $9.7 \%$, close to the $10.8 \%$ uptake based on respondents' choices.

Figure 2 shows how the predicted uptake varies by interval between injections, risk of complications and outof-pocket cost, assuming that the physician recommends the injection. Recognizing that $76.2 \%$ of the respondents were found to be non-adopters and would not likely purchase an injection, the highest predicted uptake was estimated to be $19.3 \%$ for an injection that lasts 1 year, poses no risk of complications, is free and is recommended by a physician.

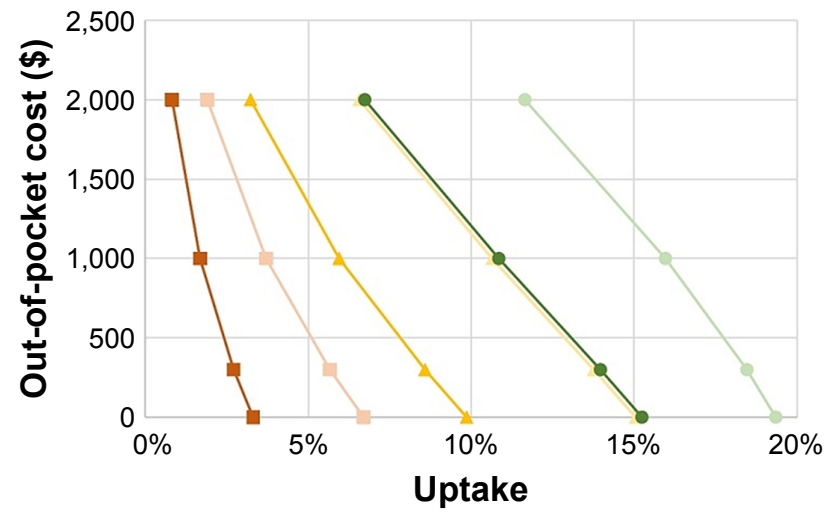

$$
\begin{aligned}
& \rightarrow-\text { Injection every } 3 \mathrm{~m}, 0.1 \% \text { risk }- \text { Injection every } 12 \mathrm{~m}, 0.1 \% \text { risk } \\
& \rightarrow \text { Injection every } 3 \mathrm{~m}, 0.01 \% \text { risk }- \text { Injection every } 12 \mathrm{~m}, 0.01 \% \text { risk } \\
& \rightarrow \text { Injection every } 3 \mathrm{~m}, 0 \% \text { risk } \rightarrow \text { Injection every } 12 \mathrm{~m}, 0 \% \text { risk }
\end{aligned}
$$

Figure 2 Predicted uptake for injections.

Notes: Uptake calculations assume that there is only one type of injection in the market as an alternative to eye drops. The calculations assume that physician recommends the injection.

Abbreviation: m, months. 
There was no stated demand for an injection that was administered 4 times a year, poses $0.10 \%$ risk, costs $\$ 2,000$ per year and is not recommended by a physician.

Risk of complications had the largest effect on uptake. For an injection that is administered every 3 months, costs $\$ 600$ per year and is recommended by the physician, reducing the risk from $0.1 \%$ to $0.01 \%$ triples uptake from $2.2 \%$ to $7.4 \%$ and reducing the risk to $0 \%$ increases uptake to $12.6 \%$.

\section{Discussion}

The goal of this study was to understand parents' experiences and attitudes about their children's use of regular eye drops for chronic eye diseases and to explore whether they would ever consider opting for an injectable solution for their child and if so, the product-specific and family-specific factors that influence that decision.

Results showed that the vast majority of parents did not find administration of eye drops to be inconvenient nor did their children complain about having to use daily eye drops. Furthermore, only half of participants stated concerns about the consequences of non-compliance. For these reasons, it is not surprising that the DCE showed little demand for the injectable solution; more than three-fourth of parents were deemed "out of the market" based on the DCE results. Yet, there was a subset of parents, those whose children administered the drops themselves, those who were concerned about the consequences of non-compliance and whose children had other chronic disease requiring regular medication, who showed strong interest in the new technology. This suggests that the primary appeal to parents of this new technology is the potential health gains from greater compliance, as opposed to the convenience factor of parents not having to administer daily eye drops.

Even for those parents who might consider the new technology, demand was highly responsive to the levels of the product features, with risk of complications being the most important factor. This is consistent with parents focusing largely on the health gains when considering whether or not to adopt this technology. In fact, any risk of complications had a significant negative influence on demand; a prototypical product with absolutely zero risk had a predicted uptake of $12.6 \%$, whereas increasing risk of a moderate side effect to just $0.01 \%$ reduces demand by nearly $50 \%$. This suggests that for a product to be successful in this market, the risks of even moderate side effects must be extremely low. Interval between injections, out-of-pocket cost and a physician's recommendation also influence demand; however, first and foremost, parents need to be reassured that the product is safe for their child to even consider it.
This study has several limitations. First, participants were told to state their preference in a hypothetical scenario, which may not reflect their actual behavior when faced with a real scenario. However, hypothetical questions were necessary since the technology is not currently available in the market yet. Second, parents were used as a proxy for their children on questions related to their children's use of regular eye drops. However, parents' knowledge or observation about their children's view may not be completely accurate. In addition, parents were assumed to be the sole decision maker on choosing a delivery method. Although parents are likely to consider their children's opinion on using a new delivery system or remaining on eye drops, they are likely to be the final decision makers. Third, we used a convenience sample of parents of children with chronic eye conditions who are not representative of those in Singapore; thus, results may not generalize to other conditions and/or other patient groups. The predominant disease in this study was myopia, which neither leads to blindness as imminently as other eye diseases like glaucoma nor causes uncomfortable symptoms that affect the child's activities on a daily basis. Uptake would differ if the mix of conditions were skewed toward other conditions. Fourth, demand for an injectable solution was calculated assuming that it is the only available new technology in the market. If there are more than one type of such products in the market, the predicted uptake would be shared by all available new technologies. Fifth, we found that a physician's recommendation was the least important factor in parents' decisions. However, the effect of physician's recommendations on decisions is likely to be higher when parents receive a recommendation from their children's physician in person, especially from one that they have an ongoing relationship with, compared to a hypothetical recommendation. Finally, respondents were told to assume that the injectable solution would be at least as effective as eye drops, with greater effectiveness resulting for children who are not fully adherent. Future studies can explore how providing specific effectiveness information affects parents' and children's willingness to opt for injections.

In conclusion, this study shows that parents of children with chronic eye disease do not find administration of daily eye drops to be a significant burden such that most would not consider alternative forms of delivery. However, a small subset of parents, primarily those whose children administer the eye drops themselves, those concerned about the consequences of non-compliance and/or those whose child has other chronic disease requiring regular medication, would consider the injectable solution if risk of complications were extremely small and efficacy is at least as good as daily drops. 


\section{Acknowledgment}

The study received internal support from Duke-NUS Medical School.

\section{Disclosure}

Dr Wong is a co-founder of Peregrine Ophthalmic Pte Ltd. The other authors report no conflicts of interest in this work.

\section{References}

1. AGIS. The relationship between control of intraocular pressure and visual field deterioration. The AGIS Investigators. Am J Ophthalmol. 2000;130(4):429-440.

2. Kass MA, Heuer DK, Higginbotham EJ, et al. The ocular hypertension treatment study: a randomized trial determines that topical ocular hypotensive medication delays or prevents the onset of primary openangle glaucoma. Arch Ophthalmol. 2002;120(6):701-713.

3. Anderson DR, Drance SM, Schulzer M. The effectiveness of intraocular pressure reduction in the treatment of normal-tension glaucoma. Am J Ophthalmol. 1998;126(4):498-505.

4. Lavik E, Kuehn MH, Kwon YH. Novel drug delivery systems for glaucoma. Eye (Lond). 2011;25(5):578-586.
5. Wong TT, Novack GD, Natarajan JV,Ho CL, Htoon HM, Venkatraman SS Nanomedicine for glaucoma: sustained release latanoprost offers a new therapeutic option with substantial benefits over eyedrops. Drug Deliv Transl Res. 2014;4(4):303-309.

6. Bond L, Nolan T. Making sense of perceptions of risk of diseases and vaccinations: a qualitative study combining models of health beliefs, decision-making and risk perception. BMC Public Health. 2011; 11(1):943.

7. Gurmankin AD, Baron J, Hershey JC, Ubel PA. The role of physicians' recommendations in medical treatment decisions. Med Decis Making 2002;22(3):262-271.

8. Marshall DA, Johnson FR, Phillips KA, Marshall JK, Thabane L, Kulin NA. Measuring patient preferences for colorectal cancer screening using a choice-format survey. Value Health. 2007;10(5):415-430.

9. Farooqui MA, Tan YT, Bilger M, Finkelstein EA. Effects of financial incentives on motivating physical activity among older adults: results from a discrete choice experiment. BMC Public Health. 2014;14(1):141

10. Johnson FR, Ozdemir S, Phillips KA. Effects of simplifying choice tasks on estimates of taste heterogeneity in stated-choice surveys. Soc Sci Med. 2010;70(2):183-190.

11. Özdemir S, Mohamed AF, Johnson FR, Hauber AB. Who pays attention in stated-choice surveys? Health Econ. 2010;19(1):111-118.

12. Orme BK. Getting Started With Conjoint Analysis. Madison, WI Research Publishers LLC; 2006.
Clinical Ophthalmology

\section{Publish your work in this journal}

Clinical Ophthalmology is an international, peer-reviewed journal covering all subspecialties within ophthalmology. Key topics include: Optometry; Visual science; Pharmacology and drug therapy in eye diseases; Basic Sciences; Primary and Secondary eye care; Patien Safety and Quality of Care Improvements. This journal is indexed on

Submit your manuscript here: http://www.dovepress.com/clinical-ophthalmology-journal

\section{Dovepress}

PubMed Central and CAS, and is the official journal of The Society of Clinical Ophthalmology (SCO). The manuscript management system is completely online and includes a very quick and fair peer-review system, which is all easy to use. Visit http://www.dovepress.com/ testimonials.php to read real quotes from published authors. 